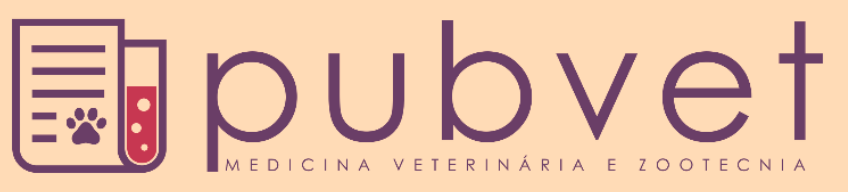

https://doi.org/10.31533/pubvet.v13n3a288.1-12

\title{
Suplementação de betaína na dieta de suínos em terminação: Revisão
}

\author{
Dante Teixeira Valente Júnior ${ }^{1} \bullet$, Marcos Henrique $\operatorname{Soares}^{2} \bullet$, Lívia Maria dos Reis $\operatorname{Barbosa}^{2} \bullet$, \\ Gustavo Amorim Rodrigues ${ }^{3}$, Matheus Balduino Gonçalves dos Reis ${ }^{1}$, Maykelly da Silva \\ Gomes $^{3 \bullet}$, Alysson Saraiva ${ }^{4 *} \bullet$ \\ ${ }^{I}$ Discente de Mestrado, Programa de Pós-Graduação em Zootecnia, Universidade Federal de Viçosa, Viçosa, MG, Brasil. \\ ${ }^{2}$ Discente de Doutorado, Programa de Pós-Graduação em Zootecnia, Universidade Federal de Viçosa, Viçosa, MG, Brasil. \\ ${ }^{3}$ Discente de Graduação em Zootecnia, Viçosa, MG, Brasil. \\ ${ }^{4}$ Professor da Universidade Federal de Viçosa, Departamento de Zootecnia, Viçosa, MG, Brasil. \\ *Autor para correspondência. E-mail: alysson_zoo@yahoo.com.br
}

Resumo. O aumento na deposição de gordura e da conversão alimentar durante a fase de terminação são fatores que implicam diretamente na qualidade da carne e também na rentabilidade da cadeia produtiva. Apesar disso, o abate tardio dos suínos pode resultar em benefícios para o frigorífico, pela redução dos custos operacionais por suíno abatido e melhor utilização dos equipamentos, bem como vantagens econômicas para o produtor resultantes da diluição dos custos de produção. Portanto, a suplementação de betaína na ração de suínos de linhagens com maior potencial para deposição de músculo, é uma estratégia para aumentar a deposição de tecido magro e minimizar a deposição de gordura. Em vista disso, objetivou-se com este trabalho, apresentar e discutir os mecanismos de ação, finalidades e resultados recentes de estudos na literatura sobre a suplementação desse modificador de carcaça na ração de suínos em terminação. A betaína atua principalmente como doadora de grupos metil, que aumentam a disponibilidade de metionina para a deposição proteica. Em relação ao seu efeito osmoprotetor, a betaína se acumula no interior das organelas celulares, protegendo-as contra estresses osmóticos e iônicos, o que reduz os gastos de energia para manter a homeostase, se tornando ainda mais importante durante os períodos quentes do ano.

Palavras chave: betaína, carcaça, suínos, terminação

\section{Dietary supplementation of betaine for finishing pigs: Review}

Abstract. Increasing fat deposition and feed conversion over the days in the finishing phase are factors that directly implicate in pork quality and productive profitability. Nonetheless, heavier pigs result in benefits for the slaughterhouse due lower labor and equipment costs and economic benefits resulting from the dilution of production and processing costs, as well as economic benefits for the pig producer resulting from the dilution of production costs. Therefore, dietary supplementation of betaine for finishing pigs of high leangenotypes is a strategy to increase lean tissue deposition and minimize fat deposition. Thereby, the aim of this study was to present and discuss the action mechanisms, role and recent results of dietary supplementation of this carcass modifier on performance and carcass traits in finishing pigs. Betaine acts mainly as a methyl groups donor, which increases the methionine availability for protein accretion. On osmoprotective effects, betaine accumulates in cellular organelles, protecting them against osmotic and ionic stresses, which reduce spending energy to keep the cellular homeostasis, becoming an important during the hot periods of the year.

Keywords: betaine, carcass, swine, finishing phase 


\title{
Suplementación de betaína en la dieta de cerdos en terminación: Revisión
}

\begin{abstract}
Resumen. El aumento en la deposición de grasa y de la conversión alimenticia durante la fase de terminación son factores que implican directamente en la calidad de la carne y también en la rentabilidad de la cadena productiva. Sin embargo, el sacrificio tardío de los cerdos puede resultar en beneficios para el frigorífico, por la reducción de los costes operativos por el porcino sacrificado y mejor utilización de los equipos, así como ventajas económicas para el productor resultantes de la dilución de los costes de producción. Por lo tanto, la suplementación de betaína en la ración de cerdos de linajes con mayor potencial para deposición de músculo, es una estrategia para aumentar la deposición de tejido magro y minimizar la deposición de grasa. En vista de ello, se objetivó con este trabajo, presentar y discutir los mecanismos de acción, finalidades y resultados recientes de estudios en la literatura sobre la suplementación de este modificador de carcasa en la ración de cerdos en terminación. La betaína actúa principalmente como donante de grupos metil, que aumentan la disponibilidad de metionina para la deposición proteica. En cuanto a su efecto osmoprotector, la betaína se acumula en el interior de las organelas celulares, protegiéndolas contra estrés osmóticos e iónicos, lo que reduce los gastos de energía para mantener la homeostasis, haciéndose aún más importante durante los períodos calientes del año.
\end{abstract}

Palabras clave: betaína, carcasa, cerdos, terminación

\section{Introdução}

A atividade suinícola tem grande importância no mercado mundial de carnes, fornecendo aos consumidores alimento de alto valor biológico. Atualmente, a carne suína é a mais consumida no mundo, alcançando em 2017 o total consumido de 110.588 mil toneladas (FAPRI, 2017). Devido à crescente demanda de carne suína pelo mercado, o sistema de produção foi se intensificando pelos avanços em pesquisas nas áreas de melhoramento genético, nutrição, instalações e sanidade (Nascimento et al., 2017).

Ao longo dos anos com o avanço dos programas de melhoramento genético, linhagens com menor espessura de toucinho e com maior potencial para deposição muscular foram selecionadas. Isso mudou a forma de enxergar a carne suína, pois de carne gorda passou a ser considerada saudável e magra. Estas mudanças também resultaram vantagens para o produtor, pela melhoria da eficiência alimentar e do ganho de peso dos suínos (Wood \& Whittemore, 2006). Entretanto, os suínos modernos apresentam reduzido conteúdo de gordura intramuscular, que é uma importante característica relacionada à qualidade da carne. O grau de marmorização contribui para a suculência, maciez, aroma e o sabor da carne e de seus produtos (Bridi \& Silva, 2007). A concentração mínima de gordura intramuscular na carne suína para que ela apresente qualidade aceitável para consumo é de 2,5\% (Madeira et al., 2016). Conforme Daszkiewicz et al. (2005), cerca de 84\% das carcaças comercializadas não atendem os requerimentos mínimos de gordura intramuscular para que a carne tenha qualidade satisfatória.

$\mathrm{Na}$ fase de terminação é onde ocorre a maior modificação na composição da carcaça. $\mathrm{O}$ aumento na deposição de gordura subcutânea e da conversão alimentar com o passar dos dias na terminação, são fatores que implicam diretamente na qualidade da carcaça e também na rentabilidade da cadeia produtiva. No entanto, o abate tardio dos suínos pode resultar em benefícios para o frigorífico, devido à diluição principalmente dos custos operacionais por suíno abatido e melhor utilização dos equipamentos, bem como vantagens econômicas resultantes do maior rendimento de carcaça e dos cortes comerciais (Wood \& Whittemore, 2006). Por outro lado, conforme os suínos se tornam mais pesados, a eficiência alimentar é reduzida devido ao aumento na deposição de gordura na carcaça, podendo ocasionar piora nas variáveis de desempenho e aumento dos custos de produção, além do risco de não atender o regime de classificação da carcaça do frigorifico (Marcolla et al., 2017). Dessa forma, um dos principais desafios é abater animais acima dos $100 \mathrm{~kg}$, aumentando a deposição de carne magra e gordura intramuscular, sem aumentar a deposição de gordura subcutânea na carcaça (Madeira et al., 2016). Portanto, o fornecimento de aditivos modificadores de carcaça para suínos de linhagens com maior potencial para deposição de músculo, é uma estratégia que pode contribuir para o aumento da deposição 
de tecido magro e redução da deposição de gordura (Marcolla et al., 2017). Assim, seria possível abater suínos mais pesados, sem comprometimento da qualidade da carcaça (Apple et al., 2004), juntamente com a melhoria do desempenho dos animais, tornando o sistema de produção mais rentável para o produtor.

Em vista disso, objetivou-se com esta revisão, apresentar e discutir os mecanismos de ação, finalidades e resultados recentes encontrados na literatura sobre a suplementação de betaína na dieta de suínos em terminação.

\section{Betaína}

A betaína é um tri-metil derivado da glicina, que foi encontrada e isolada por Sheibler em 1860, a partir da beterraba (Beta vulgaris) (Scheibler, 1869). É sintetizada nos tecidos de animais e vegetais, assim como em microrganismos, sendo que as principais fontes ricas em betaína, além da beterraba, são invertebrados marinhos, gérmen de trigo, farelo de trigo, canola e espinafre (Lipiński et al., 2012). Este composto é solúvel em água e praticamente insolúvel na maioria dos compostos orgânicos (Lever \& Slow, 2010), característica esta atribuída à sua carga elétrica e a presença de grupos funcionais polares (Odle et al., 2000).

Os vertebrados são incapazes de sintetizar grupos metil, portanto a dieta deve conter metil doadores, sendo que as principais fontes de grupos metil para os animais são: colina, metionina e betaína. Dentre estes, a betaína apresenta os melhores resultados como doador do grupamento metil (Lipiński et al., 2012). A betaína é formada a partir da oxidação da colina e apresenta grande importância nos processos metabólicos dos animais (Lipiński et al., 2012), atuando principalmente como fornecedora de grupos metil e como osmólito orgânico (Craig, 2004; Kidd et al., 1997; Lever \& Slow, 2010). Os grupos metil gerados pela S-adenosilmetionina (SAM) são necessários para a síntese de várias substâncias, tais como: creatina, fosfatidilcolina, carnitina, adrenalina, metilpurinas e aminoácidos metilados (Eklund et al., 2005). A betaína aumenta os níveis de metionina e SAM doando grupos metil para remetilação da homocisteína para formar metionina (Schwab et al., 2006). Com relação ao seu efeito osmoprotetor, a betaína se acumula nas organelas celulares, protegendo-as contra estresses osmóticos e iônicos. Dessa forma, a suplementação de betaína aumenta disponibilidade da metionina para exercer outras funções metabólicas, como a síntese de proteína (Øverland et al., 1999). O mesmo efeito "poupador" é observado na oxidação da colina para formar betaína, pois com a suplementação de betaína, maior será a disponibilidade de colina para atuar em processos metabólicos importantes (Craig, 2004).

Diante do exposto, a suplementação com betaína para suínos em terminação pode atuar na redução da deposição de gordura subcutânea e no aumento da deposição muscular (Albuquerque et al., 2017). Dessa forma, além da melhora na qualidade de carne, a utilização da betaína como modificador de carcaça, melhora também a rentabilidade do produtor (Dunshea et al., 2008; Suster et al., 2004). Em adição, alguns estudos indicam que a suplementação com betaína para suínos e terminação pode aumentar a deposição de gordura intramuscular (Feng et al., 1996; Huang et al., 2009). Outros autores, entretanto, não observaram diferença no ganho médio diário e na característica de carcaça de suínos em terminação suplementados com betaína (Matthews et al., 1998; Øverland et al., 1999). Deste modo, torna-se importante elucidar os diferentes mecanismos de ação da betaína sobre o metabolismo de suínos em terminação.

\section{Betaína no metabolismo da homocisteína/metionina}

A betaína é formada a partir da oxidação da colina. Para que isso ocorra é necessário que a colina seja transportada para o citoplasma da mitocôndria. Nas células hepáticas e renais a colina é catabolizada por várias reações enzimáticas (Lipiński et al., 2012). Após a formação da betaína, esta atua no ciclo da homocisteína/metionina na remetilação da homocisteína em metionina (Figura 1). Por meio dessas reações um grupo metil é liberado a partir da ativação da metionina em S-adenosilmetionina (SAM) (Eklund et al., 2005; Lipiński et al., 2012). O SAM é o principal doador de metil para todas as reações de metilação nas células (Loscalzo \& Handy, 2014). Logo, a síntese de proteína e formação de SAM compete pela metionina disponível (Eklund et al., 2005). O grupo metil doado será posteriormente utilizado para sintetizar outras substâncias importantes que são indispensáveis para processos metabólicos (Lipiński et al., 2012). Por sua vez, um SAM é degradado em S-adenosil homocisteína 
(SAH), e posteriormente em homocisteína, que seguirá duas vias metabólicas diferentes. Por um lado, a homocisteína pode ser transformada em cisteína, tendo assim um papel importante na síntese de proteínas. De outro modo, a homocisteína remetilada, dando origem novamente a uma metionina (Eklund et al., 2005). No fígado, esse processo é obtido por duas enzimas diferentes: a homocisteina metil transferase (BHMT) e a tetrahidrofolato metil transferase (THFMT). A BHMT catalisa a transferência de um grupo metil da betaína para a homocisteina, formando a metionina (Eklund et al., 2005; Lipiński et al., 2012). Após essa reação, dois grupos metil restantes formam a dimetilglicina, que em seguida é degrada em monometilglicina (sarcosina) e finalmente em glicina (Ratriyanto et al., 2009). Os fragmentos dos carbonos simples originados pela oxidação da dimetilglicina se ligam à molécula de tetrahidrofolato através de uma enzima catalisada pela THFMT para uma homocisteína, formando a metionina (Eklund et al., 2005).

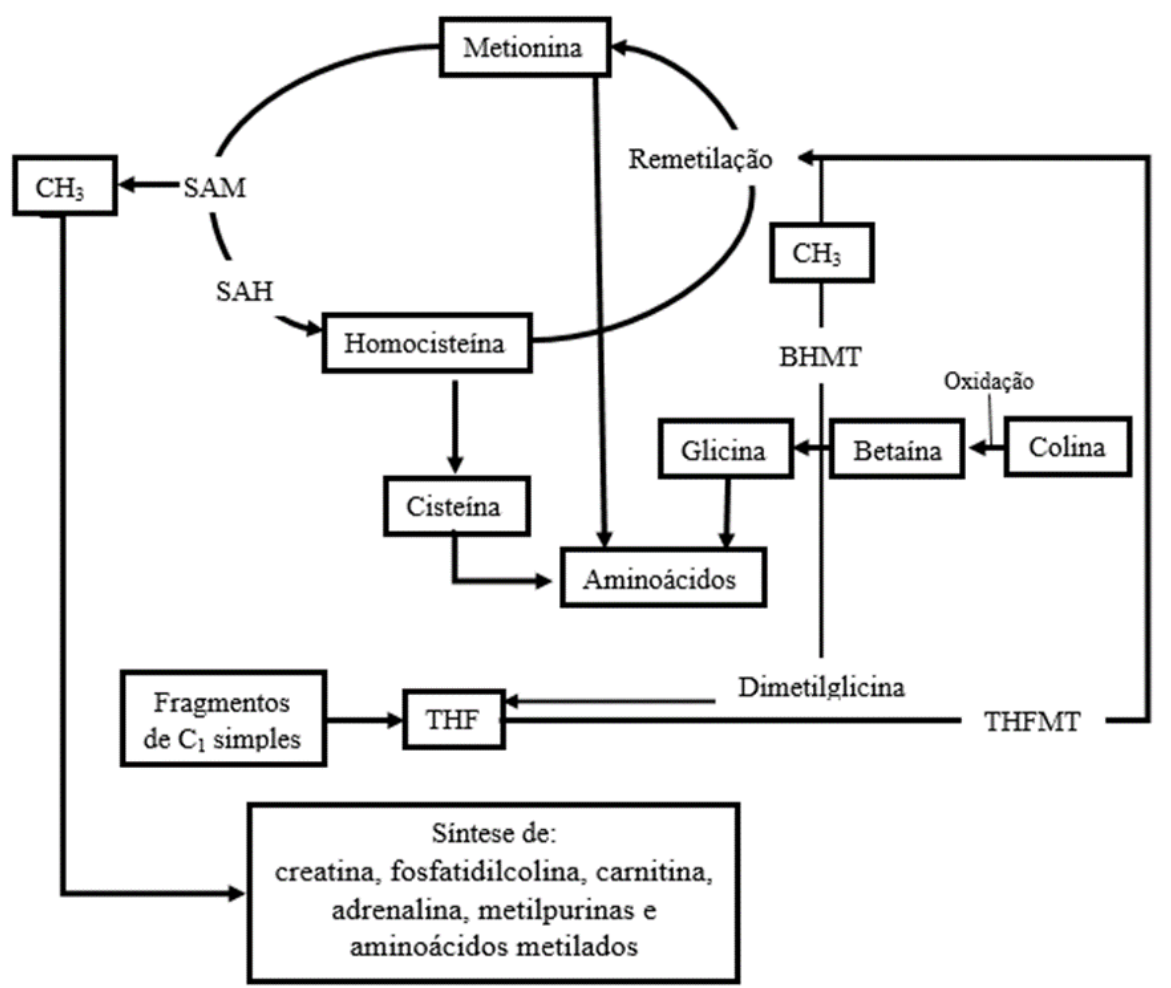

Figura 1. Ciclo betaína-metionina-homocisteína.

$\mathbf{T H F}=$ tetrahidrofolato; $\mathbf{T H F M T}=$ tetrahidrofolato metil transferase; $\mathbf{S A M}=\mathrm{S}$-adenosilmetionina; $\mathbf{S A H}=\mathrm{S}$-adenosil homocisteína; BHMT = homocisteina metil transferase. Fonte: Adaptado de Eklund et al. (2005).

Como descrito anteriormente, a homocisteína é um produto intermediário resultante da desmetilação da metionina (Eklund et al., 2005). Entretanto, altas concentrações de homocisteína no sangue pode ser prejudicial a saúde (Ganguly \& Alam, 2015). De acordo com alguns autores, várias doenças, como disfunção renal e tireoidiana, câncer, diabetes, menopausa, doenças coronárias e cardiovasculares, etc. estão associadas com altas concentrações de homocisteína no sangue (Baszczuk \& Kopczyński, 2014; Curro et al., 2014; Faeh et al., 2006; Ganguly \& Alam, 2015). Em razão disso, a betaína exerce função importante, doando o grupo metil para a homocisteína para formar metionina, que favorece a diminuição dos níveis de homocisteína do sangue (Lipiński et al., 2012).

Emmert et al. (1996); Emmert et al. (1998) observaram aumento na atividade de BHMT no fígado de suínos e aves alimentados com rações deficientes em metionina e suplementadas com colina ou betaína. Segundo Eklund et al. (2005), estes resultados mostram que a suplementação de betaína pode aumentar a taxa de remetilação da homocisteína para formar metionina, mantendo assim, SAM e homocisteína em níveis constantes no sangue.

Feng et al. (2006) suplementando betaína $(1.250 \mathrm{mg} / \mathrm{kg})$ em dietas com consumo ad libitum para suínos machos castrados (60 até $90 \mathrm{~kg}$ ), relataram que os animais suplementados com betaína tiveram aumento na atividade de BHMT no fígado. Entretanto, não observaram diferença no desempenho dos 
suínos alimentados com rações contendo betaína; porém, em relação à qualidade de carcaça, os animais suplementados com betaína tiveram redução de gordura na carcaça e na espessura de toucinho. Pesquisas utilizando roedores têm mostrado que a betaína pode aumentar a expressão gênica e a atividade de várias enzimas envolvidas na conversão de homocisteína em metionina, como por exemplo: metionina adenosil transferase 1, metil tetrahidrofolato redutase, S-adenosil hridrolase e BHMT (Kim \& Kim, 2005; Kwon et al., 2008). O aumento da atividade destas enzimas auxilia na regulação da concentração de homocisteína no fígado (Figueroa-Soto \& Valenzuela-Soto, 2018).

\section{Mecanismo antioxidante da betaína}

A peroxidação lipídica é uma das principais causas de deterioração da qualidade da carne e de seus derivados, causando a redução do "tempo de prateleira" dos produtos. As espécies reativas de oxigênio (EROS), como o radical hidroxila e o radical hidroperoxila são iniciadores da reação em cadeia que aumentam a peroxidação lipídica na carne (Min \& Ahn, 2005). Diante deste problema, nos últimos anos, as propriedades antioxidantes da betaína têm sido amplamente estudadas (Alirezaei et al., 2015; Kheradmand et al., 2013; Zhang et al., 2016). Entretanto, os mecanismos pelos quais a betaína atua na eliminação de EROS ainda não foi completamente elucidado (Zhang et al., 2016). Em geral, a betaína pode neutralizar as EROS de maneira indireta, aumentando a atividade das enzimas antioxidantes, como glutationa peroxidase (GPx), catalase (CAT), superóxido desmutase (SOD) e glutationa (GSH) (Alirezaei et al., 2015; Hoque et al., 2007).

Sabe-se que a betaína tem ação direta no ciclo metionina-homocisteína aumentando níveis de metionina e SAM. Estes possuem papel importante na neutralização das espécies reativas de oxigênio. O SAM é o principal doador biológico do grupo metil, promovendo a síntese de GSH a partir da cisteína, e também age diretamente na atividade antioxidante do sistema por meio da eliminação de EROS (Jung et al., 2013). Além disso, os resíduos de metionina nas proteínas têm ação antioxidante pelo sistema metionina sulfóxido redutase (MSR). Esses resíduos podem ser oxidados por EROS e convertidos em metionina sulfóxido (MetO), sendo posteriormente reduzidos novamente a metionina via MSR. Em cada vez que este ciclo se repete, um equivalente de EROS é eliminado (Métayer et al., 2008).

A homocisteína, precursor necessário para formação de cisteína, é um importante fator na síntese de GSH e de taurina (Kwon et al., 2008). Alguns estudos mostram que o nível de homocisteína diminui com a ação da betaína por meio da remetilação da homocisteína para metionina (Eklund et al., 2005), com isso menor será a disponibilidade de cisteína para a síntese de GSH. Entretanto, quando a disponibilidade de cisteína é baixa, a síntese de taurina é reduzida para preservar a síntese de GSH (Kwon et al., 2008). Em estudo recente, Zhang et al. (2016) avaliaram in vitro os mecanismos antioxidantes da betaína em meios contendo dicloridrato de 2,2'-azobis (2-metilpropionamidina) (AAPH), que atua gerando radicais livres, e relataram que o tratamento contendo betaína aumentou os níveis de metionina e de SAM, e diminuiu os níveis de taurina e homocisteína em relação aos tratamentos: sem AAPH e sem betaína; somente com AAPH. Contudo, os níveis de cisteína e GSH não foram alterados. Estes resultados indicam que o aumento nos níveis de metionina e SAM pode ser o mecanismo antioxidante da betaína. Segundo os mesmos autores, os níveis de cisteína e GSH não foram alterados, pois os catabolisomo da cisteína para taurina foi inibido para preservar a síntese de GSH, o que levou a diminuição dos níveis de taurina. Neste mesmo trabalho, Zhang et al. (2016) também relataram que a betaína não possui ação direta sobre a eliminação de radicais livres e não promove aumento da expressão genica de enzimas antioxidantes, tais como: GPx, CAT e SOD. No entanto, a betaína forma uma camada protetora em torno dos eritrócitos, aumentando a ação dessas antioxidases em meios contendo AAPH, sugerindo um novo mecanismo de ação, no qual a betaína contribui para a eliminação dos radicais livres e para a inibição da peroxidação lipídica.

\section{Betaína sobre a regulação osmótica}

A água possui papel vital no metabolismo celular. O mecanismo principal de regulação osmótica da célula é a osmose, na qual a água é transportada para dentro ou para fora da célula com o intuito de controlar a concentração de sais e solutos entre os meios intracelular e extracelular. Quando há desequilíbrio nas concentrações de sais e solutos entre os meios internos e externos da célula, a bomba 
de sódio-potássio é ativada para manter o balanço hídrico da célula. Entretanto, para esse mecanismo o gasto de energia é maior em relação à ação dos osmoprotetores orgânicos (Lipiński et al., 2012).

De acordo com Zabaras-Krick (1997), a molécula de betaína possui cargas positivas e negativas em uma mesma molécula, classificando-se como ziteriônica, em razão disso, ela possui propriedades osmoprotetoras. A betaína possui alta solubilidade em água, podendo se acumular em altas concentrações no citoplasma, protegendo a célula contra alterações na pressão osmótica e evitando um aumento excessivo na concentração intracelular de eletrólitos (Lipiński et al., 2012). Os osmólitos orgânicos, como a betaína, são muito importantes principalmente em situações de desidratação celular, uma vez que esses componentes ajudam a minimizar a perda de água provocada pela manutenção da osmolaridade celular (Klasing et al., 2002). Esse aumento na capacidade de retenção de água celular pode ser devido a dois mecanismos (Eklund et al., 2005). O aumento da retenção de água pode ser atribuído à capacidade osmolítica da betaína, que pode ser acumulada em altas concentrações no interior da célula. Por outro lado, a suplementação de betaína pode aumentar a absorção de mineral na célula, contribuindo para um aumento da capacidade de retenção de água no tecido muscular (Esteve-Garcia \& Mack, 2000). A atuação da betaína no controle da pressão osmótica e no aumento da retenção de água requer menos gastos de energia, pois não necessitam da ativação da bomba sódio-potássio. Com isso, a energia conservada pode ser desviada para outras finalidades, como aumentar a deposição de carne na carcaça (Schrama et al., 2003). A betaína exerce papel de osmoprotetor no interior das organelas e das células expostas aos estresses osmóticos e iônicos, repondo íons inorgânicos e protegendo enzimas, bem como as membranas celulares da inativação por íons inorgânicos (Petronini et al., 1992).

Os enterócitos lidam com meios onde a osmolaridade é muito variável, uma vez que o conteúdo intestinal é hiperosmótico em relação ao plasma sanguíneo (Mongin, 1976). Portanto, a betaína atua controlando a pressão osmótica dentro das células intestinais (Lehninger, 2006). Essa ação permite a manutenção no equilíbrio hídrico e também do volume no interior do enterócito, facilitando a secreção de enzimas digestivas (Eklund et al., 2005). Segundo Alfieri et al. (2002), células endoteliais em meios hiperosmóticos, reduzem a proliferação celular e aumentam a taxa de apoptose. A betaína atua reduzindo a taxa de apoptose e aumentando a proliferação celular em meios hiperosmóticos (Alfieri et al., 2002; Eklund et al., 2005). Com isso, a suplementação de betaína pode aumentar a digestibilidade, bem como a área de absorção dos nutrientes (Eklund et al., 2005). Schrama et al. (2003) observaram que a suplementação de betaína para suínos em crescimento melhora o aproveitamento da energia absorvida pelo animal, pois pode diminuir a produção de calor, devido ao efeito osmoprotetor da betaína. Entretanto, Mendoza et al. (2017) avaliaram a suplementação de $2.000 \mathrm{mg}$ de betaína/kg e 5 e 8.8 ppm de ractopamina para suínos em estresse por calor nas fases de crescimento e terminação, respectivamente, e observaram que não houve melhora para nenhuma das variáveis de desempenho ou de características de carcaça nos animais suplementados com betaína.

\section{Betaína sobre o metabolismo lipídico}

A betaína é um aditivo considerado 'modificador de carcaça' (Eklund et al., 2005). Esse produto, não tóxico e estável quimicamente, tem sido utilizado na nutrição de suínos com o intuito de reduzir a deposição de gordura e aumentar o tecido magro (Albuquerque et al., 2017). Algumas pesquisas mostraram que a suplementação de betaína na dieta de suínos reduz a porcentagem de gordura na carcaça (Wang et al., 2004) e aumenta o conteúdo de gordura intramuscular (Huang et al., 2009; Martins et al., 2012). Na última década, vários resultados de pesquisa vêm demostrando que a betaína pode modificar o metabolismo lipídico dos mamíferos, classificando-se como um composto lipotrópico (Lipiński et al., 2012). O papel metabólico que a betaína exerce na regulação da deposição no tecido adiposo ainda não está bem definido (Lawrence et al., 2002). Segundo Huang et al. (2009), a redução na deposição de gordura no tecido adiposo, quando se adiciona betaína na dieta de suínos em crescimento e terminação, é explicada pelo aumento na taxa de lipólise e/ou pela redução na taxa de lipogênese. Várias enzimas estão envolvidas na regulação desses processos; porém, a ação que elas exercem ainda não está clara (Li et al., 2011; Shan et al., 2009). Entretanto, de acordo com Madeira et al. (2016), a betaína pode atuar no metabolismo lipídico no tecido adiposo muscular e subcutâneo devido à regulação diferencial de alguns genes. 
Como metil doador, a betaína aumenta síntese de carnitina e fosfadilcolina, que atuam diretamente no metabolismo lipídico. A fosfadilcolina é um fosfolipídio importante na absorção e no transporte de ácidos graxos, que está presente na parede intestinal. Por outro lado, a carnitina é responsável pelo transporte de ácidos graxos de cadeia média e longa para dentro da mitocôndria, onde ocorre a $\beta$ oxidação (Huang et al., 2009). De acordo com Feng et al. (2006), a suplementação de betaína aumenta o conteúdo de carnitina no fígado e nos músculos dos suínos, indicando um efeito da betaína na redução da porcentagem de gordura na carcaça. Como a betaína está envolvida no ciclo da remetilação da homocisteína para metionina, a disponibilidade de homocisteína para produção de acetil-CoA será reduzida (Baker \& Czarnecki, 1985). Portando, a síntese de ácidos graxos e consequentemente a deposição serão atenuadas pela falta de substrato disponível (Lawrence et al., 2002).

A carnitina palmitol transferase I (CPT1) é uma enzima que atua na regulação do metabolismo lipídico. Essa enzima catalisa a conversão de ácidos graxos de cadeia longa para acilcarnitinas na presença de L-carnitina (Huang et al., 2009). A reação catalisada pela CPT1 é o primeiro passo na oxidação de ácidos graxos em todos os tecidos, que é regulada por seu inibidor fisiológico malonil-CoA (McGarry \& Brown, 1997). Dessa forma, Huang et al. (2009) avaliaram a suplementação de betaína $(1.250 \mathrm{mg} / \mathrm{kg}$ ) para suínos dos 50 aos $90 \mathrm{~kg}$, alimentados à vontade. Os autores relataram que a inclusão de betaína na ração diminuiu a atividade da CPT1 no tecido muscular, levando ao aumento do conteúdo de gordura intramuscular na carcaça. Além disso, os resultados mostraram que os animais suplementados apresentaram maior ganho médio diário, mas não houve diferenças na eficiência alimentar e no consumo de ração médio diário. Entretanto, os animais que consumiram a ração suplementada com betaína apresentaram aumento na proporção da massa muscular e também redução da proporção de tecido adiposo e na espessura de toucinho.

A betaína pode induzir a ativação e subsequente aumento da atividade da AMPK (Wang et al., 2013), que por sua vez atua na ativação de fatores e enzimas relacionadas ao catabolismo lipídico como PPAR $\alpha$ e CPT1 (Lee et al., 2006). O PPAR $\alpha$ é um importante fator relacionado à oxidação lipídica e o aumento da sua atividade promove aumento do catabolismo lipídico (Wang et al., 2013).

O transporte de ácidos graxos pela membrana plasmática é mediado por algumas proteínas, incluindo ácidos graxos translocase/cluster de diferenciação (FAT/CD 36) e proteínas transportadoras de ácidos graxos (FATP1) (Nickerson et al., 2009). FABP3 é outra importante proteína no transporte de ácidos graxos, que transporta estes do sarcolema para serem metabolizados (Hertzel \& Bernlohr, 2000). De acordo com Li et al. (2017), a suplementação de betaína para suínos em terminação nos níveis de 1250 $\mathrm{mg} / \mathrm{kg}$ e $2500 \mathrm{mg} / \mathrm{kg}$, aumentou a expressão dos genes de FAT/CD36 e FATP1 e $2500 \mathrm{mg} / \mathrm{kg}$ aumentou a expressão de FABP3 no músculo Longissimus dorsi, promovendo maior síntese de ácidos graxos. Por outro lado, esses autores também observaram aumento na expressão dos genes ligados à oxidação lipídica no músculo como AMPK $\alpha 2$, PPAR $\alpha$ e CPT1. Entretanto, a razão síntese/oxidação foi maior no tecido muscular dos animais suplementados com betaína, aumentando a gordura intramuscular. No entanto, em estudo com suínos machos inteiros em terminação (60 a $90 \mathrm{~kg}$ ), Madeira et al. (2016) não observaram efeito da suplementação de betaína $(3.300 \mathrm{mg} / \mathrm{kg})$ e/ou $1,5 \%$ de arginina em dietas com proteína bruta reduzida sobre o conteúdo de gordura intramuscular, ou sobre o conteúdo de gordura na carcaça e espessura de toucinho. No entanto, a suplementação dietética de betaína afetou a composição de ácidos graxos no músculo (Longissimus lumborum) e no tecido adiposo subcutâneo. Yang et al. (2009) estudaram o efeito da suplementação de níveis crescentes $(0,2.000,4.000$ e $6.000 \mathrm{mg} / \mathrm{kg})$ de betaína sobre o desempenho e qualidade de carne de fêmeas suínas em terminação (65 a $100 \mathrm{~kg}$ ) e verificaram que a suplementação dietética de betaína diminuiu a concentração de colesterol total no sangue e aumentou a razão dos níveis de ácidos graxos saturados/insaturados no músculo. Além disso, observaram aumento no ganho médio diário e melhora na eficiência alimentar, demostrando que a suplementação com betaína melhorou o desempenho e a eficiência alimentar desses animais.

O PPAR $\gamma$ é um receptor nuclear, que em sua forma ativa, regula o desenvolvimento do tecido adiposo e aumenta a deposição de gordura (Ding et al., 2000). A lipoproteína lipase (LPL) é considerada o principal fator que determina a deposição lipídica nos tecidos, uma vez que os substratos necessários para a biossíntese de triacilgricerol (TGL) no músculo são decorrentes da hidrólise de lipoproteínas circulantes pela LPL (Frayn et al., 2006; Tan et al., 2011). Portanto, é possível inferir que o aumento das expressões dos genes de PPAR $\gamma$ e LPL no tecido muscular indica aumento da lipogênese no tecido 
intramuscular. Em estudo recente, Albuquerque et al. (2017) avaliaram a suplementação de betaína $(1.000 \mathrm{mg} / \mathrm{kg})$ para suínos da raça Alentejano nas fases de crescimento e terminação, e observaram aumento na expressão de LPL nos músculos $L$. lumborum e $B$. femoris nos animais que consumiram a ração com betaína o que pode estar relacionado com o aumento da gordura intramuscular. Desta maneira, podemos inferir que a suplementação de betaína na dieta de suínos pode aumentar a gordura intramuscular, sem que haja aumento de gordura subcutânea, pois os mecanismos de ação no metabolismo lipídico são diferentes nos dois tecidos.

\section{Betaína sobre a utilização de energia e no metabolismo proteico}

Como já mencionado nesta revisão, a betaína possuí papel osmorregulador na célula, com isso, a betaína pode reduzir as exigências de energia para manutenção, aumentando a energia disponível para crescimento (Dunshea et al., 2008). Essa teoria está de acordo com vários autores que observaram que os benefícios da suplementação da betaína se tornam mais aparente quando as dietas dos animais possuem baixo valor energético (Dunshea et al., 2008; Schrama et al., 2003; Suster et al., 2004). Por estar envolvida diretamente no ciclo homocisteína-metionina e por ser formada a partir da oxidação da colina, a betaína pode aumentar a disponibilidade de metionina e colina (Eklund et al., 2005). Estes aminoácidos possuem grande importância na deposição proteica. Pouco se sabe sobre a atuação da betaína no metabolismo proteico de forma direta.

A suplementação de betaína também está relacionada com a redução de ureia circulante no sangue (Xu et al., 1999). Indicando melhor aproveitamento do nitrogênio para a deposição proteica (Coma et al., 1995). Avaliando o efeito da suplementação de betaína $(1.250 \mathrm{mg} / \mathrm{kg})$ na secreção pulsátil do hormônio do crescimento $(\mathrm{GH})$ e nos metabólitos séricos em suínos machos castrados e fêmeas em terminação, Huang et al. (2009) observaram aumento do GH e redução de 21,7\% da concentração sérica de ureia dos animais suplementados. Sobre as variáveis de desempenho, os autores relataram aumento de 5,45\% no ganho médio diário (GMD) dos animais suplementados com betaína em relação ao tratamento controle, no entanto, não verificaram diferenças sobre a conversão alimentar e o consumo médio diário.

Temperaturas elevadas no alojamento de suínos em terminação aumentam o estresse osmótico, o que reduz a síntese proteica devido à baixa disponibilidade hídrica da célula. A betaína, em resposta ao estresse osmótico, pode reduzir o bombeamento de íons envolvidos na regulação osmótica e aumentar a turgidez celular, aumentando a disponibilidade hídrica e possibilitando maior síntese proteica (Petronini et al., 1992).

Kathirvel et al. (2010) observaram que a suplementação de betaína aumenta a fosforilação da tirosina do substrato receptor de insulina 1, que consequentemente altera os níveis de fosforilação Akt e aumenta a disponibilidade de glicose para síntese proteica. No entanto, este efeito não é restrito somente ao tecido muscular (Figueroa-Soto \& Valenzuela-Soto, 2018). Alguns resultados de pesquisas mostram que os níveis de suplementação abaixo de $1.250 \mathrm{mg}$ de betaína/kg na ração de suínos em terminação não melhoraram as variáveis de desempenho dos animais (Nakev et al., 2009; Wang et al., 2015). Nakev et al. (2009) testaram o efeito da suplementação de betaína $(1.000 \mathrm{mg} / \mathrm{kg})$ na ração de suínos machos castrados e fêmeas em terminação por um período de 32 dias, e não observaram diferenças em relação ao desempenho entre os tratamentos e entre os sexos. Wang et al. (2015) avaliaram os efeitos da suplementação de $1.000 \mathrm{mg}$ de betaína/kg e $10 \mathrm{~g}$ de CLA $/ \mathrm{kg}$ em rações de suínos machos castrados dos 60 aos $95 \mathrm{~kg}$ alimentados com 30\% de resíduos de destilaria secos solúveis (DDGS) durante 42 dias, e não observaram efeito da betaína em nenhuma das variáveis de desempenho analisadas.

Os resultados da suplementação de betaína para suínos em terminação na literatura são pouco consistentes, principalmente em virtude da concentração e do tempo de fornecimento utilizados. Concentrações acima de $1.250 \mathrm{mg}$ de betaína/ $\mathrm{kg}$ de ração proporcionam melhoras nas variáveis de desempenho, entretanto suplementações acima de $2.000 \mathrm{mg}$ de betaína/kg de ração tem demonstrado eficácia em promover melhorias nas características de carcaça de suínos. O efeito benéfico da betaína no desempenho e nas características de carcaça é observado quando a suplementação ocorre por período mínimo de 40 dias. 


\section{Considerações finais}

A betaína é potencialmente uma alternativa nutricional para suínos em terminação, pois pode promover melhorias no desempenho e nas características quantitativas e qualitativas da carcaça. Entretanto, a utilização deste aditivo como modificador de carcaça apresenta resultados variáveis e pouco consistentes, tornando necessário maior número de pesquisas para esclarecer os mecanismos de ação, bem como o nível de inclusão e o tempo de suplementação.

\section{Referências bibliográficas}

Albuquerque, A., Neves, J. A., Redondeiro, M., Laranjo, M., Felix, M. R., Freitas, A., . . Martins, J. M. (2017). Long term betaine supplementation regulates genes involved in lipid and cholesterol metabolism of two muscles from an obese pig breed. Meat Science, 12425-33.

Alfieri, R. R., Cavazzoni, A., Petronini, P. G., Bonelli, M. A., Caccamo, A. E., Borghetti, A. F. \& Wheeler, K. P. (2002). Compatible osmolytes modulate the response of porcine endothelial cells to hypertonicity and protect them from apoptosis. The Journal of Physiology, 540(2):499-508.

Alirezaei, M., Khoshdel, Z., Dezfoulian, O., Rashidipour, M. \& Taghadosi, V. (2015). Beneficial antioxidant properties of betaine against oxidative stress mediated by levodopa/benserazide in the brain of rats. The Journal of Physiological Sciences, 65(3):243-252.

Apple, J. K., Maxwell, C. V., Brown, D. C., Friesen, K. G., Musser, R. E., Johnson, Z. B. \& Armstrong, T. A. (2004). Effects of dietary lysine and energy density on performance and carcass characteristics of finishing pigs fed ractopamine. Journal of Animal Science, 82(11):3277-3287.

Baker, D. H. \& Czarnecki, G. L. (1985). Transmethylation of homocysteine to methionine: efficiency in the rat and chick. The Journal of Nutrition, 115(10):1291-1299.

Baszczuk, A. \& Kopczyński, Z. (2014). Hyperhomocysteinemia in patients with cardiovascular disease. Postepy Higieny i Medycyny Doswiadczalnej, 68579-589.

Bridi, A. M. \& Silva, C. A. (2007). Métodos de avaliação de carcaça e da carne suína. Londrina, Paraná, Brasil: Editora Midiograf.

Coma, J., Carrion, D. \& Zimmerman, D. R. (1995). Use of plasma urea nitrogen as a rapid response criterion to determine the lysine requirements of pigs. Journal of Animal Science, 73472-481.

Craig, S. A. S. (2004). Betaine in human nutrition. The American Journal of Clinical Nutrition, 80(3):539-549.

Curro, M., Gugliandolo, A., Gangemi, C., Risitano, R., Ientile, R. \& Caccamo, D. (2014). Toxic effects of mildly elevated homocysteine concentrations in neuronal-like cells. Neurochemical Research, 39(8):1485-1495.

Daszkiewicz, T., Bąk, T. \& Denaburski, J. (2005). Quality of pork with a different intramuscular fat (IMF) content. Polish Journal of Food and Nutrition Sciences, 14(1):31-35.

Ding, S. T., Schinckel, A. P., Weber, T. E. \& Mersmann, H. J. (2000). Expression of porcine transcription factors and genes related to fatty acid metabolism in different tissues and genetic populations. Journal of Animal Science, 78(8):2127-2134.

Dunshea, F. R., Cadogan, D. J. \& Partridge, G. G. (2008). Dietary betaine and ractopamine combine to increase lean tissue deposition in finisher pigs, particularly gilts. Animal Production Science, 49(1):65-70.

Eklund, M., Bauer, E., Wamatu, J. \& Mosenthin, R. (2005). Potential nutritional and physiological functions of betaine in livestock. Nutrition Research Reviews, 18(1):31-48.

Emmert, J. L., Garrow, T. A. \& Baker, D. H. (1996). Hepatic betaine-homocysteine methyltransferase activity in the chicken is influenced by dietary intake of sulfur amino acids, choline and betaine. The Journal of Nutrition, 126(8):2050-2058.

Emmert, J. L., Webel, D. M., Biehl, R. R., Griffiths, M. A., Garrow, L. S., Garrow, T. A. \& Baker, D. H. (1998). Hepatic and renal betaine-homocysteine methyltransferase activity in pigs as affected by dietary intakes of sulfur amino acids, choline, and betaine. Journal of Animal Science, 76(2):606610 . 
Esteve-Garcia, E. \& Mack, S. (2000). The effect of DL-methionine and betaine on growth performance and carcass characteristics in broilers. Animal Feed Science and Technology, 87(1-2):85-93.

Faeh, D., Chiolero, A. \& Paccaud, F. (2006). Homocysteine as a risk factor for cardiovascular disease: should we (still) worry about it? Swiss Medical Weekly, 136(47-48):745-756.

FAPRI. (2017). Food and Agricultural Policy Research Institute. Food and Agricultural Policy Research Institute, from http://www.fapri.iastate.edu/tools/outlook.aspx

Feng, J., Liu, X., Wang, Y. Z. \& Xu, Z. R. (2006). Effects of betaine on performence, carcass characteristics and hepatic betaine-homocysteine methyltransferase activity in finishing barrows. Asian-Australasian Journal of Animal Sciences, 19(3):402-405.

Feng, P., Hunt, C. W., Pritchard, G. T. \& Julien, W. E. (1996). Effect of enzyme preparations on in situ and in vitro degradation and in vivo digestive characteristics of mature cool-season grass forage in beef steers. Journal of Animal Science, 74(6):1349-1357.

Figueroa-Soto, C. G. \& Valenzuela-Soto, E. M. (2018). Glycine betaine rather than acting only as an osmolyte also plays a role as regulator in cellular metabolism. Biochimie, 14789-97.

Frayn, K. N., Arner, P. \& Yki-Järvinen, H. (2006). Fatty acid metabolism in adipose tissue, muscle and liver in health and disease. Essays in Biochemistry, 4289-103.

Ganguly, P. \& Alam, S. F. (2015). Role of homocysteine in the development of cardiovascular disease. Nutrition Journal, 14(6):1-10.

Hertzel, A. V. \& Bernlohr, D. A. (2000). The mammalian fatty acid-binding protein multigene family: molecular and genetic insights into function. Trends in Endocrinology \& Metabolism, 11(5):175-180.

Hoque, M. A., Okuma, E., Banu, M. N. A., Nakamura, Y., Shimoishi, Y. \& Murata, Y. (2007). Exogenous proline mitigates the detrimental effects of salt stress more than exogenous betaine by increasing antioxidant enzyme activities. Journal of Plant Physiology, 164(5):553-561.

Huang, Q. C., Han, X. Y., Xu, Z. R., Yang, X. Y., Chen, T. \& Zheng, X. T. (2009). Betaine suppresses carnitine palmitoyltransferase I in skeletal muscle but not in liver of finishing pigs. Livestock Science, 126(1-3):130-135.

Jung, Y. S., Kim, S. J., Ahn, C. W., Kim, Y. S., Choi, D. W. \& Kim, Y. C. (2013). Alleviation of alcoholic liver injury by betaine involves an enhancement of antioxidant defense via regulation of sulfur amino acid metabolism. Food and Chemical Toxicology, 62292-298.

Kathirvel, E., Morgan, K., Nandgiri, G., Sandoval, B. C., Caudill, M., Bottiglieri, T., . . Morgan, T. R. (2010). Betaine improves non alcoholic fatty liver and associated hepatic insulin resistance: a potential mechanism for hepatoprotection by betaine. American Journal of Physiology-Heart and Circulatory Physiology, 2991068-1077.

Kheradmand, A., Alirezaei, M. \& Dezfoulian, O. (2013). Cadmium-induced oxidative stress in the rat testes: protective effects of betaine. International Journal of Peptide Research and Therapeutics, 19(4):337-344.

Kidd, M. T., Ferket, P. R. \& Garlich, J. D. (1997). Nutritional and osmoregulatory functions of betaine. World's Poultry Science Journal, 53(2):125-139.

Kim, S. K. \& Kim, Y. C. (2005). Effects of betaine supplementation on hepatic metabolism of sulfurcontaining amino acids in mice. Journal of Hepatology, 42(6):907-913.

Klasing, K. C., Adler, K. L., Remus, J. C. \& Calvert, C. C. (2002). Dietary betaine increases intraepithelial lymphocytes in the duodenum of coccidia-infected chicks and increases functional properties of phagocytes. The Journal of Nutrition, 132(8):2274-2282.

Kwon, D. Y., Jung, Y. S., Kim, S. J., Park, H. K., Park, J. H. \& Kim, Y. C. (2008). Impaired sulfuramino acid metabolism and oxidative stress in nonalcoholic fatty liver are alleviated by betaine supplementation in rats. The Journal of Nutrition, 139(1):63-68.

Lawrence, B. V., Schinckel, A. P., Adeola, O. \& Cera, K. (2002). Impact of betaine on pig finishing performance and carcass composition. Journal of Animal Science, 80(2):475-482.

Lee, W. J., Kim, M., Park, H.-S., Kim, H. S., Jeon, M. J., Oh, K. S., . . Park, J. Y. (2006). AMPK activation increases fatty acid oxidation in skeletal muscle by activating PPAR $\alpha$ and PGC-1. Biochemical and Biophysical Research Communications, 340(1):291-295. 
Lehninger, N. D. L. (2006). Principios de bioquímica. São Paulo.

Lever, M. \& Slow, S. (2010). The clinical significance of betaine, an osmolyte with a key role in methyl group metabolism. Clinical Biochemistry, 43(9):732-744.

Li, F. N., Li, L. L., Yang, H. S., Yuan, X. X., Zhang, B., Geng, M. M., . . Yin, Y. L. (2011). Regulation of soy isoflavones on weight gain and fat percentage: evaluation in a Chinese Guangxi minipig model. Animal, 5(12):1903-1908.

Li, S., Wang, H., Wang, X., Wang, Y. \& Feng, J. (2017). Betaine affects muscle lipid metabolism via regulating the fatty acid uptake and oxidation in finishing pig. Journal of Animal Science and Biotechnology, 8(1):1-9.

Lipiński, K., Szramko, E., Jeroch, H. \& Matusevičius, P. (2012). Effects of betaine on energy utilization in growing pigs-A review. Annals of Animal Science, 12(3):291-300.

Loscalzo, J. \& Handy, D. E. (2014). Epigenetic modifications: basic mechanisms and role in cardiovascular disease. Pulmonary Circulation, 4(2):169-174.

Madeira, M. S., Rolo, E. A., Alfaia, C. M., Pires, V. R., Luxton, R., Doran, O., . . Prates, J. A. M. (2016). Influence of betaine and arginine supplementation of reduced protein diets on fatty acid composition and gene expression in the muscle and subcutaneous adipose tissue of cross-bred pigs. British Journal of Nutrition, 115(6):937-950.

Marcolla, C. S., Holanda, D. M., Ferreira, S. V., Rocha, G. C., Serão, N. V. L., Duarte, M. S., . . . Saraiva, A. (2017). Chromium, CLA, and ractopamine for finishing pigs. Journal of Animal Science, 95(10):4472-4480.

Martins, J. M., Neves, J. A., Freitas, A. \& Tirapicos, J. L. (2012). Effect of long-term betaine supplementation on chemical and physical characteristics of three muscles from the Alentejano pig. Journal of the Science of Food and Agriculture, 92(10):2122-2127.

Matthews, J. O., Southern, L. L., Pontif, J. E., Higbie, A. D. \& Bidner, T. D. (1998). Interactive effects of betaine, crude protein, and net energy in finishing pigs. Journal of Animal Science, 76(9):2444-2455.

McGarry, J. D. \& Brown, N. F. (1997). The mitochondrial carnitine palmitoyltransferase system - from concept to molecular analysis. European Journal of Biochemistry, 244(1):1-14.

Mendoza, S. M., Boyd, R. D., Zier-Rush, C. E., Ferket, P. R., Haydon, K. D. \& van Heugten, E. (2017). Effect of natural betaine and ractopamine $\mathrm{HCl}$ on whole-body and carcass growth in pigs housed under high ambient temperatures. Journal of Animal Science, 95(7):3047-3056.

Métayer, S., Seiliez, I., Collin, A., Duchêne, S., Mercier, Y., Geraert, P.-A. \& Tesseraud, S. (2008). Mechanisms through which sulfur amino acids control protein metabolism and oxidative status. The Journal of Nutritional Biochemistry, 19(4):207-215.

Min, B. \& Ahn, D. U. (2005). Mechanism of lipid peroxidation in meat and meat products-A review. Food Science and Biotechnology, 14(1):152-163.

Mongin, P. (1976). Ionic constituents and osmolality of the small intestinal fluids of the laying hen. British Poultry Science, 17(4):383-392.

Nakev, J., Popova, T. \& Vasileva, V. (2009). Influence of dietary betaine supplementation on the growth performance and carcass characteristics in male and female growing-finishing pigs. Bulgarian Journal of Agricultural Science, 15(3):263-268.

Nascimento, C. A. M. S., Ribeiro, N. M., Rocha, L. L. \& Lucena, L. R. R. (2017). Avaliação de curvas de crescimento em suínos. Archivos de Zootecnia, 66(255):317-323.

Nickerson, J. G., Alkhateeb, H., Benton, C. R., Lally, J., Nickerson, J., Han, X.-X., . . Glatz, J. F. C. (2009). Greater transport efficiencies of the membrane fatty acid transporters FAT/CD36 and FATP4 compared with FABPpm and FATP1 and differential effects on fatty acid esterification and oxidation in rat skeletal muscle. Journal of Biological Chemistry, 284(24):16522-16530.

Odle, J., Heo, K. N. \& Lin, X. (2000). The role of carnitine and betaine in lean growth modulation of swine. Asian-Australasian Journal of Animal Sciences, 13(Special):386-395. 
Øverland, M., Rørvik, K. \& Skrede, A. (1999). Effect of trimethylamine oxide and betaine in swine diets on growth performance, carcass characteristics, nutrient digestibility, and sensory quality of pork. Journal of Animal Science, 77(8):2143-2153.

Petronini, P. G., De Angelis, E. M., Borghetti, P., Borghetti, A. F. \& Wheeler, K. P. (1992). Modulation by betaine of cellular responses to osmotic stress. Biochemical Journal, 282(1):69-73.

Ratriyanto, A., Mosenthin, R., Bauer, E. \& Eklund, M. (2009). Metabolic, osmoregulatory and nutritional functions of betaine in monogastric animals. Asian-Australasian Journal of Animal Sciences, 22(10):1461-1476.

Scheibler, C. (1869). Ueber das betain, eine im safte der zuckerrüben (Beta vulgaris) vorkommende pflanzenbase. Berichte der deutschen chemischen Gesellschaft, 2(1):292-295.

Schrama, J. W., Heetkamp, M. J. W., Simmins, P. H. \& Gerrits, W. J. J. (2003). Dietary betaine supplementation affects energy metabolism of pigs. Journal of Animal Science, 81(5):1202-1209.

Schwab, U., Törrönen, A., Meririnne, E., Saarinen, M., Alfthan, G., Aro, A. \& Uusitupa, M. (2006). Orally administered betaine has an acute and dose-dependent effect on serum betaine and plasma homocysteine concentrations in healthy humans. The Journal of Nutrition, 136(1):34-38.

Shan, T., Wu, T., Reng, Y. \& Wang, Y. (2009). Breed difference and regulation of the porcine adipose triglyceride lipase and hormone sensitive lipase by TNFa. Animal Genetics, 40(6):863-870.

Suster, D., Leury, B. J., King, R. H., Mottram, M. \& Dunshea, F. R. (2004). Interrelationships between porcine somatotropin (pST), betaine, and energy level on body composition and tissue distribution of finisher boars. Australian Journal of Agricultural Research, 55(9):983-990.

Tan, B., Yin, Y., Liu, Z., Tang, W., Xu, H., Kong, X., . . S Smith, S. B. (2011). Dietary L-arginine supplementation differentially regulates expression of lipid-metabolic genes in porcine adipose tissue and skeletal muscle. The Journal of Nutritional Biochemistry, 22(5):441-445.

Wang, L., Chen, L., Tan, Y., Wei, J., Chang, Y., Jin, T. \& Zhu, H. (2013). Betaine supplement alleviates hepatic triglyceride accumulation of apolipoprotein $\mathrm{E}$ deficient mice via reducing methylation of peroxisomal proliferator-activated receptor alpha promoter. Lipids in Health and Disease, 12(1):1-9.

Wang, L. S., Shi, Z., Gao, R., Su, B. C., Wang, H., Shi, B. M. \& Shan, A. S. (2015). Effects of conjugated linoleic acid or betaine on the growth performance and fatty acid composition in backfat and belly fat of finishing pigs fed dried distillers grains with solubles. Animal, 9(4):569-575.

Wang, Y. Z., Xu, Z. R. \& Feng, J. (2004). The effect of betaine and DL-methionine on growth performance and carcass characteristics in meat ducks. Animal Feed Science and Technology, 116(12):151-159.

Wood, J. \& Whittemore, C. (2006). Pig meat and carcass quality. Whittemore's science and practice of pig production. Oxford, UK: Editora Blackwell Publishing.

Xu, Z., Wang, M. \& Huai, M. (1999). Approach of the mechanism of growth-promoting effect of betaine on swine. Chinese Journal of Veterinary Science, 19(4):399-403.

Yang, H. S., Lee, J. I., Joo, S. T. \& Park, G. B. (2009). Effects of dietary glycine betaine on growth and pork quality of finishing pigs. Asian-Australasian Journal of Animal Sciences, 22(5):706-711.

Zabaras-Krick, B. (1997). Betaine improves energy utilisation. International Pig Topics, 12(5):12-14.

Zhang, M., Zhang, H., Li, H., Lai, F., Li, X., Tang, Y., . . Wu, H. (2016). Antioxidant mechanism of betaine without free radical scavenging ability. Journal of Agricultural and Food Chemistry, 64(42):7921-7930.

Recebido: 13 de fevereiro, 2019

Aprovado: 2 de março, 2019

Publicado: 20 de março, 2019.

Licenciamento: Este artigo é publicado na modalidade Acesso Aberto sob a licença Creative Commons Atribuição 4.0 (CC-BY 4.0), a qual permite uso irrestrito, distribuição, reprodução em qualquer meio, desde que o autor e a fonte sejam devidamente creditados. 